\title{
A FANTASIA NO CIBERESPAÇO: \\ A DISPONIBILIZAÇÃO DE MÚLTIPLOS ROTEIROS VIRTUAIS PARA A SUBJETIVIDADE
}

Márcio Rimet Nobre e Jacqueline de Oliveira Moreira

Márcio Rimet Nobre
Mestre em
Psicologia
pela PUC/MG,
especialista em
Teoria Psicanalítica
pela UFMG.
Jacqueline de Oliveira
Moreira
Doutora em
Psicologia Clínica
pela PUC/SP, mestre
em Filosofia pela
UFMG, professora
do Programa de
Pós-Graduação
(strito sensu) em
Psicologia da PUC/
MG.

RESUMO: A partir da leitura das teorias freudianas sobre a fantasia, buscaremos apontar a importância desta dimensão para a adesão do sujeito pós-moderno ao computador. A atual experiência desse sujeito na internet baseia-se nos novos roteiros para a aventura fantasística, o que inaugura novo locus para o laço social e para a ação da subjetividade. Em Freud, a fantasia complementa, ao lado do desejo inconsciente, a realidade psíquica, ambas fundamentais para a psicanálise. No cruzamento entre a realidade virtual e a psíquica, vislumbramos novos roteiros para esta última, quando o sujeito depara-se com substitutos do desejo, na experiência do prazer on-line.

Palavras-chave: Realidade virtual, realidade psíquica, fantasia, ciberespaço, pós-modernidade.

\begin{abstract}
The fantasy in cyberspace: the availability of multiple virtual tours for subjectivity. From a reading of Freudian theories about the fantasy, we point to the importance of this dimension for membership of the postmodern subject to the computer. The current experience of this subject on the internet is based on the new routes for the fantasistic adventure, which opens a new locus for social bonding and action of subjectivity. For Freud, fantasy complements beside the unconscious desire, psychic reality, and fundamental to psychoanalysis. At the intersection between virtual reality and psychological envision new pathways for the latter, where the subject is faced with replacement of desire, the experience of pleasure online.
\end{abstract}

Keywords: Virtual reality, psychic reality, fantasy, cyberspace, post-modernity. 
A emergência da realidade virtual, por meio das novas tecnologias digitais da comunicação, e seus impactos sobre a realidade psíquica, mais particularmente sobre a fantasia na pós-modernidade, ${ }^{1}$ representa a preocupação central do presente ensaio teórico. A proposta, entretanto, não se resume em demonstrar a pertinência conceitual da fantasia para a psicanálise. A intenção é partir de uma compreensão dessa categoria para nos debruçarmos sobre um fenômeno sociocultural bastante específico que vem se mostrando cada vez mais presente na vida cotidiana por todo o planeta: a relação do indivíduo pós-moderno com a realidade virtual do ciberespaço, sendo a internet o principal meio para essa experiência.

Segundo a maioria dos autores que discutem a historicidade do tema, o termo cyberspace foi introduzido na literatura de ficção científica em 1984 pelo escritor cyberpunk William Gibson, em seu clássico Neuromancer. Gibson compreende o ciberespaço como o resultado de um conjunto de redes de computadores por onde circulariam todas as informações em diversos formatos, tratando-se de um espaço não físico ou territorial:

"O ciberespaço gibsoniano é uma "alucinação consensual". A Matrix, como chama Gibson, é a mãe, o útero da civilização pós-industrial onde os cibernautas vão penetrar. Ela será povoada pelas mais diversas tribos, onde os cowboys do ciberespaço circulam em busca de informações. A Matrix de Gibson, como toda a sua obra, faz uma caricatura do real, do quotidiano." (LEMOS, 2008, p.127)

Em suas obras, Pierre Lévy buscou definir o ciberespaço, mas com a preocupação anterior de problematizar o que compreendemos por virtual: aquilo que existe em potência, e, portanto, pode ser atualizado. Nesse caso, o virtual não antagoniza com o real, mas sim com o atual, realizando-se na atualização. Assim, para Lévy, o ciberespaço constitui um espaço de interação e comunicação entre as pessoas que, intermediado pelas conexões entre redes de computadores, faz circular informações de natureza digital, tendo como suporte o virtual (LÉVY, 1996, p.15-18; 1999, p.92-93).

Para Lemos, o ciberespaço "se encontra preso em estruturas arcaicas, imaginárias e simbólicas de toda a vida em sociedade” (2008, p.127) e pode ser definido como um lugar poroso e rizomático a funcionar como uma espécie de

\footnotetext{
${ }^{1}$ Optamos por adotar a expressão pós-modernidade por entendê-la adequada para indicar nossa concordância com a ideia de que mudanças fundamentais estiveram em curso ao longo do último século, abrangendo praticamente todas as dimensões da vida social. É justamente por seu caráter bastante genérico que o termo se mostra suficiente para a finalidade do presente trabalho, uma vez que não constitui nosso objetivo enveredarmos pelos meandros da discussão sociológica.
} 
inteligência coletiva. Por ele, segundo o autor, "toda a economia, a cultura, o saber, a política do século XXI, vão passar (e já estão passando)” (idem). A partir do ciberespaço, conforme sustenta Lemos, vários de nossos valores e padrões serão revistos e noções fronteiriças — como as do real e do virtual, do individual e do coletivo — serão redefinidas, entre diversas outras.

Lemos compreende o ciberespaço a partir de duas perspectivas principais: "como o lugar onde estamos quando entramos num ambiente simulado (realidade virtual), e como o conjunto de redes de computadores, interligados ou não, em todo o planeta, a internet." (2008, p.128). Tal como a primeira perspectiva de Lemos, compreendemos o termo ciberespaço como algo maior que a internet. Aqui, entretanto, utilizaremos o conceito com referência restrita à experiência do espaço virtual da internet. O ciberespaço é o ambiente em que se configura essa nova forma de realidade: a realidade virtual e seu mundo à parte, suporte para novo âmbito de ação e experimentação para a subjetividade. Assim, para além de toda a invasão tecnológica que esse inusitado contexto entorna sobre nosso pensamento ainda moderno, a realidade virtual do ciberespaço acolhe de maneira irresistível nossa subjetividade, propiciando verdadeiros voos, ou, no jargão, navegações infinitas. Nesse locus, as comunidades virtuais constituem ambientes de conexão que propiciam novas formas de relações sociais, sejam elas estabelecidas em caráter ocasional ou duradouro, em que grandezas como espaço geográfico ou tempo não entram como fatores limitadores.

Nossa aposta supõe que essa aventura traga consequências irreversíveis para a subjetividade contemporânea, tal a sua abrangência sobre o atual estágio de nossa civilização. Assim, importa-nos saber em que medida as novas tecnologias produzem efeitos sobre a configuração fantasística daqueles que se lançam no mar do ciberespaço, inaugurando novo lugar para o laço social e para a lida com a realidade.

Interessam-nos, mais especificamente, os reflexos dessa relação sobre a fantasia, isto é, sobre esse dispositivo psíquico que permite ao sujeito lidar, a um só tempo, com as exigências pulsionais do Isso (id) e com a realidade material, atuando como mediadora desse conflito. É nessa tensão entre tais exigências e a crueza de uma realidade cada vez mais hostil e desidealizada que a internet se insere como suporte para uma experiência de prazer imediato, acessível e onipresente (LEITÃO \& NICOLACI-DA-COSTA, 2005), o que atende não apenas à fugacidade da fantasia, mas também à tendência contemporânea ao hedonismo e ao autorreferencialismo, ao lado dos extremos de um individualismo narcísico e alienante.

A internet é um imenso sistema de redes de computadores interligados mundialmente entre si, que possibilitam a comunicação de forma fácil e rápida, funcionando como emissores e receptores de informação. Utilizam, para isso, 
um conjunto de protocolos de comunicação denominados TCP/IP. Os meios para efetuar essas ligações são diversos, e incluem rádio, linhas telefônicas, linhas digitais, satélite, fibra óptica etc. Sabemos que, do ponto de vista metapsicológico, a fantasia está no limiar dos sistemas psíquicos e é dotada de uma mobilidade que lhe permite livre passagem entre eles. Sendo assim, em meio a essa parafernália tecnológica, perguntamo-nos: a fantasia pode se beneficiar com essas diferentes ofertas da internet?

Antes de respondermos a tal pergunta, porém, faz-se necessário apresentar uma definição de fantasia que funcione como baliza metodológica. Optamos pela definição de Laplanche e Pontalis, no clássico Vocabulário da psicanálise: "Roteiro imaginário em que o sujeito está presente e que representa, de modo mais ou menos deformado pelos processos defensivos, a realização de um desejo e, em última análise, de um desejo inconsciente” (1996, p.169).

Nessa definição, verificamos ser possível isolar três principais aspectos norteadores para a discussão: a fantasia como roteiro imaginário; o sujeito como protagonista do fenômeno fantasístico; e a realização do desejo inconsciente como causa primeira desse fenômeno.

Para efeito das reflexões seguintes, consideraremos o usuário imersivo, isto é, aquele que, independentemente de idade, sexo ou outras condições socioculturais, mantém com a rede uma relação mais próxima. Essa relação não precisa ser medida em horas de navegação ou qualquer outro parâmetro quantitativo. Entendemos, portanto, o usuário imersivo como aquele que não apenas utiliza a internet para fins de trabalho, serviços, pesquisas pontuais ou como aparato de comunicação, mas o que vai além: usufrui dela como "mais” um meio de socialização, trocas afetivo-sexuais, lazer, diversão e entretenimento. Nessa medida, nosso recorte privilegia, mais uma vez, o aspecto qualitativo do uso da rede.

\section{A FANTASIA COMO ROTEIRO IMAGINÁRIO}

O termo "roteiro" nos remete à ideia de algo ordenado sequencialmente e sob alguma lógica. Já em sua correspondência com Wilhelm Fliess, Freud (1950/1996) revela que a fantasia é composta não apenas por elementos inconscientes e respeitantes à sexualidade, mas também por reminiscências de memórias remotas do sujeito, geralmente referentes aos primeiros anos de vida. Essas memórias ficaram impressas sob a forma de resquícios sensoriais: sons, cheiros, fragmentos de imagens. Nesse roteiro, dificilmente poderíamos discernir o que é da ordem de um ou outro de seus componentes, sobretudo pelo fato de nele estarmos mergulhados em cada momento de nossa existência, não sendo possível descolarmo-nos de nossa própria realidade psíquica. 
Certamente, a complexidade do aparelho psíquico proposto por Freud (1923) não nos permite isolar com facilidade as ações psíquicas e seus agentes. Assim, ao pensarmos um ordenamento sequencial dessa natureza, não podemos creditá-lo, por exemplo, a um trabalho deliberado de maneira tão direta pelo Eu (ego).

É certo que a atividade fantasística possui um caráter defensivo e, como tal, age sob custódia da porção inconsciente desse mesmo Eu (ego). Dessa forma, a fantasia respeita um grau de autonomia característico dos processos inconscientes. Nessa autonomia, portanto, a lógica utilizada passa a ser a desse sistema, diferente daquela que esperaríamos de uma ação puramente consciente da instância egoica, guiada, talvez, pela razão.

Seguindo essa outra lógica, e de maneira concatenada, a teia fantasística recobre a totalidade de nossa vida, de modo que seu caráter fronteiriço e extremamente móvel lhe permite grande circulação entre os sistemas psíquicos - o que talvez seja sua principal função para a subjetividade. Mais que qualquer outro mecanismo de defesa do Eu (ego), a fantasia parece amortecer o choque entre os interesses a serem defendidos por essa instância, limando as diferenças e nos fazendo crer em nossa realidade interna experimentada como única, isto é, a realidade psíquica.

\section{INTERNET: UM MUNDO DE POSSIBILIDADES}

A internet, por meio de uma gama de conteúdos imagéticos e textuais, oferece diversos roteiros virtuais como convite para o exercício da fantasia. A estrutura rizomática de hiperlinks/hipertextos funciona como os índices remissivos das antigas enciclopédias. Por meio do clique do mouse, o usuário encontra o fio pelo qual percorre a trajetória labiríntica do ciberespaço, que funciona como uma Cnossos $^{2}$ digital. Da mesma forma, por meio das ferramentas de busca, pode encontrar amigos esquecidos na infância ou até deparar com informações sobre si mesmo. Funcionando como verdadeiros oráculos pós-modernos, tais ferramentas disponibilizam, de forma instantânea, todo e qualquer tipo de conhecimento produzido pela aldeia global até o momento, em diferentes níveis de aprofundamento. Qualquer tentativa de se listar essas possibilidades soaria, no mínimo, ingênua.

Particularmente, os sites e as páginas de relacionamento exercem especial atração sobre o usuário da rede. Proliferam com números incríveis as "redes sociais” como Orkut, Facebook e My Space, que expõem informações pessoais ínti-

\footnotetext{
${ }^{2}$ Cnossos foi a cidade cretense onde o rei Minos mandou construir um labirinto gigantesco, habitado pelo minotauro, ser híbrido mitológico que aterrorizava os habitantes e exigia sacrifício humano.
} 
mas, além do Twitter e dos blogs; os sites de relacionamento — como Parperfeito. com.br, Disponível.com.br, Aondenamoro.com, Solteiroscomfilhos.com — por meio dos quais o usuário realiza buscas afetivo-sexuais, encontrando inclusive páginas específicas para seus interesses. Nas interfaces de interatividade instantânea, como MSN Messenger, Skype ou UOL Chat, o usuário entra em contato direto e em tempo real com os demais navegantes, podendo trocar imagens pessoais por meio de web cams.

Acreditamos que a maior parte dos sujeitos apresenta uma relação instrumental com tais dispositivos da internet. Entretanto, esse fato não invalida o projeto de refletir sobre os possíveis impactos desse aparato sobre a subjetividade. É nessa medida que a navegação na internet constitui um novo refúgio para as fantasias sexuais, pois permite ao usuário explorar os cantos mais íntimos de seu próprio roteiro psíquico, por meio dos roteiros do ciberespaço. Nesses sites, o usuário expõe e explora com clareza suas fantasias, publiciza seus gostos e preferências e tece em detalhes sua própria descrição física, munindo seu provável interlocutor com o mesmo tipo de informação que dele espera obter.

Para Lima (2009), os processos discursivos da internet revelam uma comunicação viva, característica da oralidade. Aliado a isso, está o fato de que o usuário usufrui dessa vivacidade sem deixar de se proteger de uma exposição inicial exagerada, podendo esconder-se sob dados falsos, como nome, idade e local de residência, e somente revelar sua verdadeira identidade caso seja movido por algum interesse mais específico.

Ainda nos anos 1990, Turkle enumera alguns dos roteiros no campo da fantasia sexual que os usuários podem desfrutar a partir do encontro com o virtual:

“Embora não pareça ser uma tendência generalizada, encontrei várias mulheres que diziam apresentar-se como personagens masculinas para poderem ter netsex com outros homens. Algumas pessoas têm relações sexuais na pele de personagens nãohumanas (...). Algumas gostam de sexo a dois. Outras usam a realidade virtual como um lugar para terem experiências de sexo em grupo.” (TURKLE, 1997, p.333)

A autora considera as diversas dificuldades que tais comportamentos poderiam desencadear na vida comum dos usuários, originando "enormes confusões de ordem prática e emocional” (TURKLE, 1997, p.333). Desse modo, a “prática” de sexo no ambiente virtual imporia certa proteção, algo como um isolamento, contra os agentes morais da sociedade, devido ao seu caráter secreto e reservado. Considera, entretanto, que mesmo na realidade virtual não se está isento de enfrentar dificuldades e constrangimentos, mas, nesse caso, tudo pode ser contornado de modo mais fácil, o que dependerá da capacidade de cada usuário para lidar com as situações, tal como ocorreria também na vida cotidiana. 
Ainda que a internet represente, por excelência, o campo do imaterial, para muitos usuários, a socialização ou o sexo virtuais têm o mesmo valor das relações concretas e, como tal, são reais, ainda que virtuais. Para Lévy (1996), o virtual e o real não são excludentes. Tal como a fantasia, o virtual não se confunde com o que não é real, posto que o irreal é o que não existe. Ao contrário, tanto o virtual quanto a fantasia abrem caminho para o que pode se atualizar, isto é, para aquilo que já possui existência em alguma dimensão. Parece-nos importante ressaltar que a utilização do termo real nessa reflexão não se vincula com a proposta lacaniana. Tal como em Lévy, o real aqui é pensando como sinônimo de realidade, ou seja, refere-se àquilo que encontra alguma materialidade ou concretude para os sentidos.

No espaço cibernético, a realidade virtual possibilita a atualização da fantasia, na medida em que engendra um paralelismo com a realidade cotidiana ou material, o que propicia novo espaço de ação para o homem pós-moderno. A diferença consiste em que os relacionamentos possam se efetivar ou não, abandonando o recinto da realidade virtual e tomando corpo na vida concreta, o que dependerá de todos os interesses em jogo, além das barreiras tradicionais de tempo e espaço. Assim, dois usuários poderão, por exemplo, teclar e se relacionar a partir de pontos geográficos absolutamente distantes: conhecer-se, saber das preferências um do outro, vislumbrar cenas domésticas a partir de suas web cams etc. A dificuldade poderá se apresentar quando decidirem encontrar-se pessoalmente, o que incluirá os demais sentidos, como o olfato, o toque, a temperatura etc., além dos efeitos da proximidade física sobre as reações e o comportamento geral, a serem percebidas presencialmente. Para isso, esses usuários dependerão de uma série de outros fatores situacionais em suas vidas.

\section{O SUJEITO DO PRAZER: O PRINCIPIO DO LIVRE FLUXO DE ENERGIA}

Assim como o sono, a atividade no ambiente virtual mostra-se também narcísica, na medida em que parece absorver o Eu (ego), retirando-o momentaneamente da realidade material. Isso não significa, necessariamente, um aprisionamento desse Eu (ego); ao contrário, pode, assim, experimentar alto grau de liberdade ao encontrar-se com uma atividade prazerosa que lhe remeta aos primórdios da vida subjetiva.

Da mesma maneira, também os roteiros virtuais soam como novos espaços de fruição e liberdade para o Eu (ego), que vislumbra outra forma de experimentar prazer. Assim, a internet apresenta novos jogos de linguagem, com os quais o sujeito precisa aprender a lidar na contemporaneidade. Nesse cruzamento entre as realidades psíquica e virtual, a diversidade de opções que tais roteiros disponibilizam para o sujeito parece, de fato, infinita, tanto em seus temas quanto 
em seus conteúdos. Por si só, essa oferta representa um convite à descoberta e, portanto, ao exercício da curiosidade humana, que não pode ser facilmente desconsiderada, sobretudo se levarmos em conta nossa tendência à busca do prazer em atividades lúdicas.

Deixado de lado no passado por obra da instância egoica, que conclama o sujeito para a realidade material do mundo adulto, o jogo é reencontrado na realidade virtual. Nesse emaranhado de roteiros, o sujeito, solto num mar de opções e novas modalidades do brincar, dá livre fluidez a sua fantasia que, por meio das reminiscências inconscientes do jogo infantil, reencontra-se com o prazer do lúdico atualizado on-line.

Mas, tal como a criança, o navegante do ciberespaço, independentemente de sua idade, pode também distinguir o que seja da ordem do virtual e da realidade material:

"Apesar de toda a emoção com que a criança catexiza seu mundo de brinquedo, ela o distingue perfeitamente da realidade, e gosta de ligar seus objetos e situações imaginados às coisas visíveis e tangíveis do mundo real. Essa conexão é tudo o que diferencia o brincar infantil do fantasiar.” (FREUD, 1908/1996, v.9, p.135)

Assim como a criança freudiana, o usuário da rede não deixa de levar a sério o mundo virtual, com suas diversas possibilidades lúdicas. Ao contrário, investe-o com a mesma seriedade e emoção, sem deixar de relacioná-lo a elementos de sua vida cotidiana. Deste modo, não perde a conexão com o mundo concreto, salvo em situações extremas. Por enquanto, basta que compreendamos que os milhares de roteiros que a realidade virtual disponibiliza na pós-modernidade se oferecem, sedutoramente, à subjetividade contemporânea, sendo a fantasia o principal gancho para esse encontro.

A realidade virtual, assim, parece propiciar uma nova modalidade de compartilhamento social, na qual o próprio imaginário se encontra em jogo. Uma vez que se compõe de elementos simbólicos provenientes do pensamento de milhões de colaboradores, a realidade virtual representa uma multiplicidade alternativa na rota da realidade psíquica, com novos roteiros imaginários digitalizados disponíveis a todos.

A subjetividade, marcada então por essa outra forma de lidar com a materialidade - ou seria virtualidade? - das coisas, sob novo enfoque quanto aos padrões de tempo e espaço, não parece querer escapar ao novo locus a ser partilhado com a alteridade. Da mesma forma, também a percepção moderna do tempo linear dá lugar a uma experiência de fragmentação, de esvaziamento e efemeridade, o que alguns autores denominam destemporalização (SIBILIA, 2008). Assim, podemos destacar ao menos duas características resultantes do híbrido entre o 
virtual e o fantasístico protagonizado pelo sujeito, patentes nos diversos estudos sobre o tema: a desterritorialização e a destemporalização.

Em tal situação, o encontro da fantasia com a realidade virtual parece mais que oportuno e apropriado, pois, por sua própria natureza inconsciente, a fantasia tende a atualizar-se de forma constante, sem respeitar balizas temporais, tal como a dinâmica do conteúdo das páginas na realidade virtual.

Da mesma maneira, em sua relação com a desterritorialização espacial, a fantasia deixa-se movimentar pelo ciberespaço, movida pelo interesse e pela curiosidade do sujeito que não mais precisa respeitar os limites físicos e as barreiras concretas da realidade material. Nesse exercício de ubiquidade, o sujeito envolve-se na fluidez da navegação, sendo levado pela nave de sua fantasia por diferentes percursos e roteiros virtuais, para acessar os símbolos culturais que povoam digitalmente o espaço virtualizado numa nova realidade.

É flagrante a analogia que podemos estabelecer entre as formas de conceber e experimentar as dimensões temporal e espacial e as características tópicas da fantasia, conforme vislumbramos com a definição proposta por Freud em seu artigo "O inconsciente":

“Por um lado, são altamente organizadas, livres de autocontradição, tendo usado todas as aquisições do sistema Cs., dificilmente distinguindo-se, a nosso ver, das formações daquele sistema. Por outro, são inconscientes e incapazes de se tornarem conscientes. Assim, qualitativamente pertencem ao sistema Pcs., mas factualmente, ao Ics.” (FREUD, 1915/1996, v.14, p.195)

Desse modo, pensando do ponto de vista tópico da metapsicologia freudiana, ao favorecer a mobilidade da fantasia, a realidade virtual termina por permitir também a própria fluidez dos conteúdos inconscientes, o que propicia ao sujeito usufruir desse plus virtual de modo mais descolado das barreiras convencionais da realidade material.

Para além da abolição do espaço como barreira para as trocas pós-modernas, importa-nos o fato de que, no virtual, o sujeito se mostra onipresente, assim como, no psiquismo, a própria fantasia também o é. A ruptura dos limites espaciais no ciberespaço parece fazer menção à livre passagem da fantasia pelos "lugares" psíquicos representados por Freud por meio da tópica dos sistemas. O caráter fronteiriço e móvel da fantasia torna-a um ser misto, conforme vimos com Freud, o que não apenas favorece sua plasticidade, mas também seu envolvimento em todo o âmbito do aparelho psíquico.

Essa onipresença da fantasia no pensamento faz com que sua interferência na ação do sujeito seja direta e ininterrupta, garantindo a constância de sua realidade psíquica durante toda a vida. Nessa medida, poderíamos pensar, conforme aponta 
Freud em A perda da realidade na neurose e na psicose (1924/1996), que não há qualquer predomínio ou privilégio da neurose na lida com a realidade material em relação à psicose. Ao contrário, se o psicótico tenta recobrar o sentido com a realidade por meio do delírio, isso ocorre exatamente pelo fato de não suportar o contato direto e não dispor desse amortecimento da fantasia. Na verdade, em sua árdua tarefa de administrar o conflito psíquico, o Eu (ego) está a meio caminho entre a realidade e a fantasia. É ele próprio quem se utiliza desta última como defesa, e não apenas quanto aos desígnios do Isso (id), mas também contra as exigências do Supereu (superego) e da crueza da realidade.

Desse ponto de vista, não há como pretender um momento de total lucidez, durante o qual pudéssemos isolar qualquer verdade concernente a uma forma pura ou objetiva da realidade material. Essa pretensa pureza no encontro com uma realidade isenta - ou precária - de atributos simbólicos e fantasísticos talvez somente possa ser pensada no campo da psicose. Não parece haver, portanto, partilha da realidade material em sua inteireza, dado que seu colorido é diferente para cada sujeito.

A experiência de compartilhamento coletivo na realidade virtual é, certamente, um dos principais elementos que convocam o sujeito, o que ocorre por meio da fantasia. É a própria fantasia que parece ser compartilhada, uma vez que cada usuário, em seu ponto geográfico, percebe-se conectado a uma estrutura maior, que ultrapassa as barreiras naturais de tempo e espaço.

Para Leitão e Nicolaci-da-Costa, ao se arvorarem pelo espaço da realidade virtual, os usuários encontram um grau de prazer que os faz experimentar novas potências psíquicas, o que concorre para mudanças na forma de conceberem vários aspectos da realidade:

"São sujeitos que derivam enorme prazer do uso de um novo espaço de vida (o espaço virtual). Neste espaço, sentem-se onipotentes e munidos de um superpoder pessoal superior ao que experimentavam nos espaços ditos reais. Também operam mudanças nas formas de perceber seus corpos, seja por meio da invenção de um corpo virtual, seja pela sensação de expansão de seu corpo real.” (LEITÃO \& NICOLACI-DA-COSTA, 2005, p.448)

Desse modo, a própria corporeidade do Eu (ego) parece estender-se imaginariamente pelos meandros do ciberespaço, onde a realidade psíquica se mistura, de certa maneira, com os elementos da realidade virtual. Vale lembrar que em O Ego e o Id, portanto, na entrada de sua segunda teoria do aparelho psíquico, Freud apresenta o Eu (ego) em uma de suas mais importantes definições: “O ego é, primeiro e acima de tudo, um ego corporal; não é simplesmente uma entidade de superfície, mas é, ele próprio, a projeção de uma superfície” (FREUD, 
1923/1996, v.19, p.39). À medida que representa a projeção de uma superfície corpórea, o Eu (ego) o faz para o próprio conjunto da subjetividade.

Conforme Lago, Moreira e Nobre (2009), entretanto, em seu papel de identificar o sujeito ao corpo, o trabalho do Eu (ego) não ocorre sem a contribuição dos elementos alteritários que entram em sua composição, num fluxo que o altera de maneira constante, graças a sua permeabilidade e a seu caráter plástico:

“(...) essa experiência interna de uma identidade não se dá descolada de uma experiência partilhada, em que o outro se insere com todo o seu peso para a constituição da subjetividade com um todo. Mas na pós-modernidade esse corpo/identidade atinge dimensões plásticas que possibilitam uma construção e reconstrução incessantes." (LAGO; MOREIRA \& NOBRE, p.56, 2009)

Desse modo, os autores apontam para o que parece ser uma tendência subjetiva na pós-modernidade, em que a identidade assume um caráter múltiplo, acolhendo com mais facilidade os matizes disponíveis pelo repertório simbólico-cultural. Nessa medida, a capacidade do Eu (ego) de resistir aos padrões sociais parece abalada, talvez devido à grande flexibilização e diversidade que esses mesmos padrões percebem atualmente, assim como as instituições, os valores e modos de vida, no que a fantasia por certo não deixará de tirar proveito no sentido de garantir algum prazer para o sujeito.

\section{O DESEJO INCONSCIENTE E AS NOVAS JANELAS PARA SUA REALIZAÇÃO}

Por fim, o caráter interativo da internet não apenas permite como também convida o sujeito a participar dessa construção ininterrupta da realidade virtual, numa experiência aparentemente fecunda de prazer. É aqui que a balança dos dois princípios de funcionamento mental postulados por Freud parece pender para o lado do prazer.

Aliada em todo esse processo e animada pelo desejo, a fantasia funciona ao mesmo tempo na vertente dos mecanismos de defesa do Eu (ego) - lembremos que ela atua como uma "fachada" para as moções inconscientes do Isso (id) ludibriando a censura e facilitando a passagem dos conteúdos pelo psiquismo. Nessa medida, sua natureza tributária da realidade psíquica inconsciente a desobriga do teste de realidade:

“Com a introdução do princípio de realidade, uma das espécies de atividade de pensamento foi separada; ela foi liberada no teste de realidade e permaneceu subordinada somente ao princípio de prazer. Esta atividade é o fantasiar, que começa já 
nas brincadeiras infantis, e, posteriormente, conservada como devaneio, abandona a dependência de objetos reais." (FREUD, 1911/1996, v.12, p.240)

Logo adiante, Freud, mais uma vez, deixa claro o desprezo dos processos inconscientes em relação ao teste de realidade: “(...) eles equiparam a realidade do pensamento com a realidade externa e os desejos com sua realização - com o fato - tal como acontece automaticamente sob o domínio do antigo princípio de prazer" (FREUD, 1911/1996, v.12, p.243).

Nessa medida, a fantasia possibilita um descanso para a instância egoica, como vimos com Freud, por exemplo, no papel dos devaneios, típicos da vida em vigília. Por sua própria natureza, a fantasia representa um escape para o Eu (ego). Ao mesmo tempo que precisa corrigir o caráter insatisfatório da realidade obedecendo ao desejo inconsciente, ela possibilita uma evasão individual, pois não é compartilhável, mas pode ser acessada a qualquer momento e, independentemente do lugar, através dos quadros psíquicos que compõe no imaginário.

Em sua tarefa de encenar o desejo, a fantasia é parceira e auxiliar do Eu (ego). Ela o acalenta e distrai de sua ingrata missão de administrar o conflito, uma vez que encontra oportunidades atuais para que o desejo se realize, conforme nos adverte Freud: “(...) o desejo utiliza uma ocasião do presente para construir, segundo moldes do passado, um quadro do futuro” (FREUD, 1908/1996, v.9, p.139).

Além disso, na tendência do aparelho psíquico de aceder ao prazer obedecendo ao desejo inconsciente, a fantasia dispõe de campo singular na experiência virtual, parecendo funcionar como um retorno à experiência arcaica de satisfação. Nesse âmbito, a própria ideia de conflito mostra-se esvaziada, pois o sujeito dispõe de uma rede de linguagens e símbolos propensos a facilitar novos encontros para o desejo. Assim, as infinitas práticas e modalidades de uso da internet funcionam como propiciadores de grande prazer para crianças, adolescentes e adultos, por meio de jogos, brincadeiras e lazer em geral, trocas sociais, experiências no campo da sexualidade, encontros afetivos, como ferramenta para comunicação, pesquisa, curiosidade ou mero passatempo.

Da mesma forma que as grandezas de tempo e espaço, também a moralidade está excluída para a fantasia e para o inconsciente. Na realidade virtual, tempo e espaço estão em fluxo, e a moralidade não está em questão. Em nosso entendimento, ela está presente com cada sujeito, visto que não há como concebê-la virtualmente.

O que muda para o sujeito a partir da relação realidade psíquica-realidade virtual, no que tange à moralidade, é o fato de que, tal como a fantasia pode ludibriar os mecanismos psíquicos que representam a regra social, ela o faz com ainda mais liberdade na intimidade de sua atividade solitária frente à tela 
do computador. Nessa medida, a regra social encontra-se mais apagada, sendo a experiência do prazer facilitada pela distância física entre os usuários, o que neutraliza a moralidade que poderia constar no laço social das relações reais:

“Através da realidade virtual, o sujeito insere-se num mundo que apresenta inúmeras possibilidades de realização de seu desejo, um mundo que não possui barreiras. Apesar de existir uma diferença entre a imagem virtual e a imagem de representação do real, o sujeito, confundindo o que é da ordem emocional com o que é virtual, lida com as imagens virtuais como possibilidades de concretizarem o mundo ideal almejado. No ciberespaço, as imagens virtuais são uma simulação do real.” (LAGO; MOREIRA \& NOBRE, 2009)

Para além dessa capacidade da realidade virtual de flexibilizar a regra social, Gevertz aponta ainda noutra direção. Para a autora, no ciberespaço "a imagem não mais representa o real, mas ela o simula" (GEVERTZ, 2002, p.267). Ao proceder a essa simulação, essa imagem não pretende representá-lo, mas sê-lo de fato: “a lógica da simulação não pretende mais representar o real com uma imagem, mas, sim, sintetizá-lo, em toda sua complexidade” (idem). Nessa perspectiva, em seu paralelismo, o ciberespaço parece apresentar-se dotado até mesmo de uma intencionalidade, o que nos conduziria a questões de ordens bastante distintas das pretensões atuais.

\section{CONSIDERAÇÕES FINAIS}

Não deve restar dúvida de que a experiência subjetiva no ciberespaço possui aspectos positivos e negativos. Se, por um lado, favorece a expansão do imaginário que parece materializar-se virtualmente aos nossos olhos, por outro, a quase ausência de limites não pode deixar de suscitar cautela quanto às consequências que possam daí advir para as gerações em formação. A experiência de prazer imediato propiciada pela rede, aliada ao individualismo narcísico e alienante que reina nas sociedades capitalistas, pode estabelecer uma combinação bombástica, que modifique de maneira profunda e irreversível a formação da subjetividade na pós-modernidade.

Assim, sob os cuidados da fantasia e, uma vez absorvido pelos roteiros imaginários do ciberespaço, o Eu (ego) pode distrair-se de sua vigilância para com a balança dos princípios do prazer e da realidade, entretendo-se perante o universo virtual.

Ao longo da história, a literatura, o teatro e, mais recentemente, o cinema, têm oferecido profícuo material para alimentar a fantasia humana. Não resta dúvida da grandeza de toda a produção humana registrada por meio dessas 
manifestações. Entretanto, pelo menos num determinado aspecto, a internet vai além dessas modalidades, na medida em que não apenas oferece conteúdo, como também abre espaço para contribuições de todo e qualquer usuário, condição que instaura a interatividade em nível sem precedentes mesmo entre os meios de comunicação. Nessa medida, o fascínio exercido pela rede sobre seus usuários quase possibilita uma equivalência entre as diferentes realidades — psíquica, virtual e material — , tal como podemos depreender da conclusão de um dos entrevistados de Turkle (1997, p.18): “a vida real é só mais uma janela (...) e normalmente não é a que mais me agrada”.

Na aposta dos diversos estudiosos, em virtude das mudanças ocorridas na pós-modernidade, o que está em questão não é apenas a permeabilidade do Eu (ego) ou do sujeito para o simbólico partilhado na realidade virtual. Como vimos, essa já é uma característica patente dessa instância, a partir do corte freudiano. O que de fato nos interessa é a forma como a subjetividade é transformada em seu próprio modo de apreender o mundo. Trata-se, portanto, de se perguntar de que maneira e por quais vias passam hoje os processos psíquicos, como a aquisição de conhecimento, a afetividade e as trocas sociais. Nessa esteira, Leitão e Nicolaci-da-Costa acenam para o delineamento de algumas dessas mudanças extraídas das contribuições dos psicólogos entrevistados em seu trabalho:

“São elas: o prazer que sentem ao usar a internet como um novo espaço de vida, a onipotência que experimentam como usuários, as formas de relação que estabelecem com seus corpos, e, finalmente, os excessos que vivem no espaço virtual.” (LEITÃO \& NICOLACI-DA-COSTA, 2005, p.444)

Para as autoras, a viagem virtual remete-nos a uma experiência de prazer, em que o sujeito se move pela curiosidade da mera diversão propiciada por seu caráter lúdico, que o induz à brincadeira e estimula sua criatividade. Essa situação traz à tona a ideia freudiana de que, na modalidade criativa, os escritores e poetas experimentam o exercício da fantasia, que flui livremente pelo espaço em branco da folha de papel (FREUD, 1908/1996, v.9).

Com respeito à onipotência, as autoras concluem que, na internet, o sujeito tem a sensação de poder acessar tudo e de tudo dispor, o que o leva a extrapolar os limites da realidade do mundo concreto. Essa onipotência propiciada pela acessibilidade - pelo próprio efeito de onipresença do sujeito navegante - ancora-se nas novas exigências do acelerado zeitgeist pós-moderno e, mais especificamente, no âmbito da realidade psíquica, na necessidade da agilidade, na pressa e na invasão de conteúdos experimentados de forma instantânea e atual.

Tal como o brincar infantil, os roteiros virtuais aliam o prazer do jogo compartilhado por meio das diversas formas dessa experiência, em que a sexualidade encontra 
terreno para brotar plenamente, protegidos que estão os internautas pela barreira da tela e do emaranhado tecnológico. No quesito sexualidade, a rede mostra-se inigualável e não deixa de ser sugestivo de que esse seja um dos roteiros preferidos da maioria dos usuários. Nesse caso, uma questão faz-se pertinente e aponta o caminho para futuras pesquisas: por que o conjunto temático sexo-erotismo-pornografia é tão acessado pelos usuários na internet?

$\mathrm{Na}$ escolha de objetos a serem investidos pela ação do Eu (ego), o desejo se faz notar pelos matizes assumidos na forma dos gostos pessoais, dos interesses e das preferências em todos os aspectos da vida, bem como da maneira de o sujeito lidar com as frustrações ou com as realizações. Para o desejo inconsciente, nada importa a respeito de barreiras físicas, temporais ou morais. Para além de todas as fronteiras - consciente ou inconsciente, virtual ou psíquica, real ou fantasística - o desejo quer realizar-se, e o que de fato importa são os traços portados pelo objeto, que poderão remetê-lo ao seu mítico objeto primevo.

Assim, a tendência econômica de nosso aparelho psíquico de poupar energia, dirá Freud, faz com que nos apeguemos às fontes de prazer que se encontram disponíveis, desde que nos remetam às várias facetas que pode o desejo assumir. Nesse caso, a realidade virtual parece fazer configurar exemplarmente, na infinidade de janelas que o ciberespaço nos permite abrir a partir da tela.

Recebido em 11/1/2011. Aprovado em 13/6/2011.

\section{REFERÊNCIASS}

FREUD, S. (1996) Edição standard brasileira das obras psicológicas completas de Sigmund Freud. Rio de Janeiro: Imago.

(1950 [1892-1899]) “Extratos dos documentos dirigidos a Fliess", v.I, p.247-384.

(1908 [1907]) “Escritores criativos e devaneios” , v.IX, p.147-160.

(1911) "Formulações sobre os dois princípios do funcionamento mental”, v.XII, p.273-288.

(1915) “O inconsciente”, v.XIV, p.185-248.

(1923) “O ego e o id”, v.XIX, p.13-86.

(1924) “A perda da realidade na neurose e na psicose”, v.XIX, p.227236.

GEVERTZ, S. (2002) Um olhar psicanalítico à sociedade contemporânea. Revista Brasileira de Psicanálise, v.36, n. 2, 263-276.

LAGO, G. C. P.; MOREIRA, J. de O.; NOBRE, M, R. (2009) A experiência do corpo no ciberespaço: o adolescer na era da realidade virtual. Anais do $6^{\circ}$ Conpsi. Belém, p. 56. 
LAPLANCHE, J.; PONTALIS, J.-B. (1996) Vocabulário da psicanálise. São Paulo: Martins Fontes.

LEITÃO, C. F.; NICOLACI-DA-COSTA, A. M. (2005) Impactos da internet sobre pacientes: a visão de psicoterapeutas. Psicologia em Estudo, Maringá, (10)3, set./dez, 441-450.

LÉVY, P. (1996) O que é o virtual? São Paulo: Editora 34. (1999) Cibercultura. São Paulo: Editora 34.

LEMOS, A. (2008) As estruturas antropológicas do ciberespaço, in LEMOS, A. Cibercultura, tecnologia e vida social na cultura contemporânea. Porto Alegre: Sulina.

LIMA, N. L. de. (2009) "A escrita virtual na adolescência: os blogs como um tratamento do real da puberdade, analisados a partir da função do romance". Tese de Doutorado, Faculdade de Educação, Universidade Federal de Minas Gerais, Belo Horizonte.

SIBILIA, P. (2008) O show do eu: a intimidade como espetáculo. Rio de Janeiro: Nova Fronteira.

TURKLE, S. (1997) A vida no ecrã: a identidade na era da internet. Lisboa: Relógio D’Água.

Márcio Rimet Nobre

marcionobre205@hotmail.com

Jacqueline de Oliveira Moreira

jackdrawin@yahoo.com.br 